\section{EMBRYRIDDLE}

Aeronautical University

SCHOLARLY COMMONS
Journal of Aviation/Aerospace

Education \& Research

Volume 9

Number 3 JAAER Spring 2000

Article 8

Spring 2000

\title{
The Scope and Status of the Fixed Base Operator/General Aviation Service Industry in Illinois
}

D. Scott Worrells

worrelld@erau.edu

Jose R. Ruiz

David A. NewMyer

newmyer@siu.edu

Follow this and additional works at: https://commons.erau.edu/jaaer

\section{Scholarly Commons Citation}

Worrells, D. S., Ruiz, J. R., \& NewMyer, D. A. (2000). The Scope and Status of the Fixed Base Operator/ General Aviation Service Industry in Illinois. Journal of Aviation/Aerospace Education \& Research, 9(3). https://doi.org/10.15394/jaaer.2000.1260

This Article is brought to you for free and open access by the Journals at Scholarly Commons. It has been accepted for inclusion in Journal of Aviation/Aerospace Education \& Research by an authorized administrator of Scholarly Commons. For more information, please contact commons@erau.edu. 


\title{
THE SCOPE AND STATUS OF THE FIXED BASE OPERATOR/GENERAL AVLATION SERVICE INDUSTRY IN ILLINOIS
}

\author{
D. Scott Worrells, Jose R. Ruiz, and David A. NewMyer
}

This paper reports on the results of a 1998 survey of 143 Fixed Base Operators (FBO's) located at 128 public use airports in Illinois. The purpose of the survey was to determine the size, scope, and status of the Illinois FBO industry. After two mailings, an overall response rate of 53 completed surveys (44.9\%) was achieved. The respondent FBO's indicated an average: (a) nine separate aviation services, (b) 6.4 aircraft owned, (c) 19.8 people employed, (d) payroll under $\$ 250,000$, (e) $\$ 500,000$ or more in annual revenue, (f) over 21 years in business, and (g) 1.1 competing FBO's on the same airport. When asked about FBO status over the past five years at local, statewide, and national levels, respondents reported that they believe local FBO numbers have remained the same and that statewide and national numbers have decreased. When asked about FBO status for the next five years, respondents reported that they believe local FBO numbers will remain the same and that statewide and national numbers will decrease. Finally, the most likely expected structural changes in the FBO industry, according to respondents, will be increased FBO specialization and more focus on corporate jet customers.

The General Aviation Revitalization Act (GARA) was signed into law August 1994 with the hope that it would "fire up" the growth in the "small end" of the general aviation field. In fact, the number of single engine general aviation aircraft manufactured since that time has blossomed (Department of Transportation: Federal Aviation Administration [DOT: FAA], 1999, p. V-11). But what about the general aviation service business located at airports that are supposed to serve this influx of new aircraft? How are these businesses doing? What is their status? Will they grow in the future?

This paper reports on a survey to determine the scope (size) and status of FBO's in the state of Illinois. As a point of clarification "Fixed Base Operator" and "general aviation service companies" are used interchangeably throughout the text. Fixed Base Operators are based at 128 public use airports throughout the state (see Appendix A). The intent of the survey was to determine the present scope and status of these FBO's and the general aviation service industry following enactment of GARA. Another purpose of the survey was to obtain the opinions of FBO respondents regarding the status of $F B O$ 's over the past five years as well as the status of FBO's over the next five years.
Respondents were asked to state their opinions about the numbers of FBO's at the local, statewide, and national levels in these time periods. Finally, they were also asked about likely structural changes in the FBO market industry, including possible closures of FBO businesses.

\section{LITERATURE REVIEW}

General Aviation is expected to sustain moderate growth of the active general aviation fleet, in hours flown, and in student pilots according to the $25^{\text {th }}$ Annual Aviation Forecast Conference in March 2000 (Lowe, 2000).

In the five years since enactment of the GARA, 25,000 new jobs have been created, GA aircraft production has increased $100 \%$, GA aircraft exports have doubled, Research and Development has increased $150 \%$, and student pilot numbers have increased as well. The strength and recovery of the industry is attributed to a strong economy and the GARA that trimmed product liability (Lowe, 2000). The unknown variable to continued growth is the price of fuel. The FAA, (as cited Lowe, 2000), warned, "If the projected scale back in fuel prices in 2001 doesn't materialize, the potential effect on U.S. and world economic growth and air travel could be considerable" ( $p$. 28). 
According to the FAA forecast for General Aviation from 1999 through 2010 business use of general aviation aircraft will grow more rapidly than personal use of general aircraft. The turbine-powered fixed wing aircraft fleet is forecast to grow at three times that of the piston-powered fixed wing aircraft fleet (DOT: FAA, 1999, p. I-16). From a pilot's perspective, an April 1998 Aircraft Owners and Pilots Association (AOPA) poll of certificated pilots, (as cited in DOT: FAA, 1999), $74.5 \%$ of AOPA members reported that the state of aviation was as good or better than it had been (p. V-11).

Harton, (as cited in Infanger, 1999), defines a Fixed Base Operator as:

A person operating under a written agreement for the use of land, buildings, or facilities at the airport for the purpose of providing to the public services required under written agreement including, without limitation... the sale of aviation fuel, ground handling services, aircraft rental and sales, (etc.). (p. 17)

He goes on to say that FBO's do best when they specialize and he identifies fuel and handling as "core services" (Infanger, 1999).

By the mid 1990's the National Aviation Transportation Association (NATA) estimated a drop in FBO numbers from more than 10,000 to less than 5,000 ; forecasting 2,000 FBO's by the year 2,000 (Phelps, 2000). However, the economy has demonstrated unparalleled growth, interest rates have dropped, increasing moderately, and fuel prices, with exception of present rates, have been reasonable. The effect this has had on the FBO industry is that today there are somewhere between 4,000 and 4,500 FBO's in the U.S. (Phelps, 2000). Twelve to fifteen percent of those have facilities and the location to specialize in servicing turbine-powered business aircraft and their passengers (Phelps, 2000). Fixed Base Operators are operating at capacity. "For the last three to five years, FBO's have enjoyed fuel flow volumes they never dreamed of in the early 1990's" (Phelps, 2000, p. 35).

Phelps (2000) identifies two perplexing issues facing the FBO industry today. The price of fuel and low profit margins; Air Traffic Control and ground-handling delays (p. 35). Neither of which does the industry exert any control over.

According to "The Aviation \& Aerospace Almanac, 1999 Edition" the state of Illinois ranks $3^{\text {rd }}$ in Active General
Aviation Aircraft in the Great Lakes Region; Nationally Illinois ranks 7th. An "active aircraft" is flown for a minimum of one hour per calendar year. In the Great Lakes Region, Michigan has the greatest number of active aircraft with 6,478 , Ohio is next with 6,377 active aircraft, and Illinois follows with 5,897 active aircraft. Nationally, California has the greatest number of active aircraft with 23,093 , Texas is next with 13,780 , then Florida with 11,398 , Michigan with 6,478, Washington has 6,379, and then Ohio, Illinois follow with previously reported numbers (p. 293).

Another area for national comparison is Airport Improvement Program funding. Here again the "The Aviation \& Aerospace Almanac, 1999 Edition" identifies Texas receiving $\$ 137,852,000$ in Federal Funds, California receiving $\$ 92,416,000$ in Federal Funds, Alaska receiving $\$ 76,651,000$ in Federal Funds, and Illinois receiving $\$ 75,463,000$ in Federal Funds in 1997 (p. 389).

\section{METHODOLOGY}

\section{Survey Participants}

A total of 143 addresses (see Appendix B) were compiled for FBO's and general aviation service companies located at the 128 public use airports across the state of Illinois. The following sources provided input to this list of addresses:

1. The Illinois Aviation Trades Association membership list for 1994-1995.

2. The World Aviation Directory (Summer 1998 edition).

3. The 1997-1998 Illinois Airport Directory.

4. The Aircraft Owners and Pilots Association Airports 1998 Directory.

\section{Survey Instrument Design}

This study utilized a mail-back, questionnaire/opinionnaire survey instrument. It was designed with the assistance of FBO owners/managers and general aviation service providers. The instrument was composed of sixteen multiple choice and short response questions designed to determine the scope and status of Illinois FBO's. Several questions were included to elicit the opinion and rationale of FBO owners/managers and general aviation service providers on the status of FBO's, locally, statewide and nationally, over the past five years and in the next five years. 


\section{Survey Results and Limitations}

The initial survey was mailed in June 1998. There were 43 usable responses received from this first mailing. Eighteen surveys were returned due to incorrect addresses. A second mailing in July resulted in 10 additional usable responses. The second mailing also had seven surveys returned due to incorrect addresses. Overall completed surveys received numbered 53 from both mailings for a return rate of $37 \%$. However, when surveys returned because of incorrect addresses (25) are factored in, the result is a net response rate of $44.9 \%$.

Three important limitations were identified in this study: (a) There were no respondents from west-central (Springfield area) or western Illinois (Moline south to Pittsfield). Ten FBOs were identified and surveyed in these areas, but none of them responded. (b) Several public Illinois airports do not have a full-time FBO on-site (at least none could be found in any of the published listings), and there is no data from airports in those geographical areas included in the study. (c) Data reported in this study are based on the perceptions and observations of FBO owners/operators within the state of Illinois.

An attempt to draw conclusive generalizations from this study related to the status and future of the FBO industry on a national level would be inappropriate. However, the data reported in this study serve as an indicator of various concerns, issues, and trends perceived to be affecting the FBO industry, locally and statewide in Illinois, and may have some applicability on a national level. The geographic distribution of the respondents is depicted in Appendix C. The Scope of the Fixed Base Operator/General Aviation

\section{SERVICE INDUSTRY}

\section{Number of FBO's}

As noted in the methodology section of this article, a total of 143 Illinois based aviation service companies, or Fixed Base Operators, were found in published sources during 1998. These 143 companies are located at 128 public use airports in the State of Illinois, with 16 airports hosting more than one FBO or aviation service company as shown in Appendix B. A total of 54 public use airports in Illinois did not have an advertised or publicly-listed FBO as indicated in Appendix D. This does not mean that these airports do not have an FBO or aviation service provider. It simply means that the sources consulted did not list one. Another point is that some privately owned public use airports may not list an FBO separately from the airport itself. In addition, a current 1998 address could not be located for 25 of the listed FBO's (these are the "incorrect addresses" indicated in the research design section of the article).

Services Provided by Respondent FBO's

Hangar rental proved to be the most popular service provided by survey respondents with $79.2 \%$ of them providing that service. This was followed in descending order by aircraft fueling, flight instruction, general aircraft maintenance, and pilot supplies. On the other hand, services such as avionics or propeller repair were provided by just over $20 \%$ of respondents, which reflects the cost of providing specialized services. See Table 1.

Aircraft Operated by Respondent FBO's

Table 2 reflects a break down of the categories, quantities, and percentages of the total number of respondent-operated aircraft. The majority of aircraft reported as operated by respondents were single engine piston aircraft. This comes as no surprise since nearly $70 \%$ of respondents provide flight instruction. However, a point of interest is that there were more, although marginally so, turbojet aircraft reported as operated by respondents than multi-engine piston aircraft.

Employment, Payroll, and Business Volume

The respondents reported a total of 1,052 employees, with $307(28.2 \%)$ of those full time and $745(71.8 \%)$ of those part-time. Also, a majority of the respondent FBO's and general aviation service companies $(62 \%)$ reported that they had an annual payroll of $\$ 250,000$ or less. Interestingly, $16 \%$ of the respondents reported a payroll above $\$ 1.0$ million. See Table 3.

Total business volume as reported by respondents ranged from less than $\$ 50,000$ annually to more than $\$ 5$ million annually. A point indicating present strength of the industry, whether related to GARA or not, is that more respondents reported annual business volume in excess of $\$ 500,000$ than those who reported annual business volume at less than $\$ 500,000$. See Table 4.

Age and Number of Competing FBO's

Illinois FBO's, according to the respondents, have been in business from 1.5 years to over 70 years. The average age among Illinois FBO's is 21 years. Illinois FBO's compete with anywhere from zero to 20 other FBO's on their airport. The average number of competing FBO's on the same airport among respondents is 1.1. 
Table 1

Services Provided for a Fee by Respondent FBO's

\begin{tabular}{lll}
\hline \multicolumn{1}{c}{ Service } & Number of Businesses Reporting & $\%$ \\
& & \\
\hline & 42 & 79.2 \\
Hangar Rental & 41 & 77.4 \\
Aircraft Fueling & 37 & 69.8 \\
Flight Instruction & 36 & 67.9 \\
General Aircraft Maintenance & 35 & 66.0 \\
Pilot Supplies & $30^{\mathrm{a}}$ & 56.6 \\
Tie Down Rental & $30^{\mathrm{a}}$ & 56.6 \\
Powerplant Maintenance & 28 & 52.8 \\
Aircraft Charters & 26 & 49.1 \\
Aircraft Sales & 17 & 32.1 \\
Sales of Food/Beverages & 12 & 22.6 \\
Avionics Repair & $11^{\mathrm{a}}$ & 20.8 \\
Propeller Maintenance & $11^{\mathrm{a}}$ & 20.8 \\
Flight/Weather Planning & 10 & 18.9 \\
Other & & \\
\hline
\end{tabular}

Note. $\underline{\underline{n}}=53 .{ }^{a}$ Represents a tie in the number of services provided. ${ }^{b}$ Other includes de-ice, pre-heat, ground power unit, towing, flying clubs, on-demand freight, and skydiving. 
Table 2

Aircraft Owned and Operated by Respondents

\begin{tabular}{llc}
\hline Category & Number & $\%$ \\
\hline & & \\
Single Engine Propeller & 202 & 59.4 \\
Multi Engine Propeller & 46 & 13.5 \\
Turbo Prop & 25 & 7.4 \\
Turbo Jet/Turbo Fan & 47 & 13.8 \\
Rotor Craft & 12 & 3.5 \\
Other & 8 & 2.4 \\
Total & 340 & 100.0 \\
\hline
\end{tabular}

Note. $\underline{n}=53 .{ }^{a}$ Other includes glider, simulators, and lease back aircraft.

Table 3

Annual Payroll of Respondent FBO's

Category

$\$ 0-\$ 50,000$

$\$ 50,000-\$ 100,000$

$\$ 100,000-\$ 250,000$

$\$ 250,000-\$ 500,000$

$\$ 500,000-\$ 1,000,000$

$\$ 1.0$ million-\$5.0 million

Above $\$ 5.0$ million
Number

12

8

11

4

7

8

0

$\%$

Note. $\underline{\underline{n}}=50$. Three respondents did not provide data in this category.

24.0

16.0

22.0

8.0

14.0

16.0

0.0 
Table 4

Total Business Volume of Respondent FBO's

\begin{tabular}{lcc}
\hline \multicolumn{1}{c}{ Category } & Number & $\%$ \\
\hline$\$ 0-\$ 50,000$ & 5 & 10.2 \\
$\$ 50,000-\$ 100,000$ & 2 & 4.1 \\
$\$ 100,000-\$ 250,000$ & 4 & 8.2 \\
$\$ 250,000-\$ 500,000$ & 61 & 2.2 \\
$\$ 500,000-\$ 1,000,000$ & 12 & 24.5 \\
1.0 million-\$5.0 million & 12 & 24.5 \\
Above $\$ 5.0$ million & 8 & 16.3 \\
\hline
\end{tabular}

Note. $\underline{\underline{n}}=49$. Four respondents did not provide data in this category.

\section{The Status of the Fixed Base Operator/General Aviation Service Industry FBOs Over the Past 5 Years}

Participants were asked the following question: "In your opinion, has the number of airport service businesses increased, decreased, or remained the same over the past five years?" Participants were asked to provide responses to this question in three categories: local, statewide, and national levels. They were given three status responses to reflect their opinions: increase, decrease, or remain the same. A total of 48 respondents provided input to this question. See Table 5. Participants were also asked to provide rationale for their opinion.

Local.

Nearly twenty three percent of respondents, indicated that airport service businesses had either increased or decreased in the past five years. Those responding that airport service businesses had increased provided the following rationale: (a) strong economy, (b) the sale of new aircraft, (c) cheap fuel prices, (d) new airport management, and (e) increased charter operations. Those that indicated a decline in airport service businesses over the past five years provided the following rationale: (a) a lack of state and local initiatives for airport services development, (b) increased costs associated with providing aircraft services, (c) product liability and frivolous lawsuits, (d) declining customer base, (e) tighter regulations, (f) shrinking manpower pool, and (g) competition with home-based operators.

Twenty-eight participants $(58.3 \%)$ reported that the number of airport service businesses remained the same over the past five years. Rationale they provided for the stability of airport service businesses during that time frame was: (a) only FBO at the airport, (b) general economic stability, (c) not enough business volume to support more than one FBO, (d) increased costs associated with providing aircraft services, (e) government regulation, and (f) lack of a customer base.

Statewide.

In this category, $16.6 \%$ of the survey participants reported that the number of airport service businesses statewide had increased over the past five years. Rationale provided for this increase by each of the respondents was "a strong economy".

Fifty percent of participants reported that the number of airport service businesses had decreased over the past five years. The number of respondents indicating a decline in airport service businesses varies proportionately with the variety of their rationale for the decline. For example: (a) a lack of state and local initiatives for airport services development, (b) increased costs associated with providing 
aircraft services, (c) product liability and frivolous lawsuits, (d) declining customer base, (e) too much government, (f) low profit margins and competition from large, name brand FBO's, (g) poor management, (h) poor marketing, (i) smaller airports cannot support a business operation without subsidies, and (j) the Press.

Almost twenty-three percent of the survey participants reported that the number of airport service businesses remained the same over the past five years. The following rationale was provided: (a) general economic stability, (b) new general aviation aircraft are too expensive, (c) facility improvements needed at most general aviation airports, and (d) new entrants to the market replacing those that had closed.

From an intrastate, regional perspective (see Appendix E), the respondent opinion of statewide FBO status for the past 5 years varies. See Table 6 .

A majority of both the north and central Illinois respondents viewed the number of statewide FBO's as decreasing over the past five years. A majority of southern Illinois respondents viewed the number of statewide FBO's as remaining the same over the past five years.

Nationally.

Referring to Table 5, an interesting point is revealed in the numbers of respondents reporting that statewide and national airport service businesses had increased over the past five years. Respondents reported a marginal $2 \%$ difference, between statewide and national numbers, for increased business. Respondent rationale for this increase was also similar: a strong economy with the addition of new aircraft sales.

Fifty-four percent of participants reported that the number of airport service businesses had decreased over the past five years. Here again the rationale provided for the decline was proportionate to the responses: (a) a lack of state and local initiatives for airport services development, (b) increased costs associated with providing aircraft services, (c) product liability and frivolous lawsuits, (d) declining customer base, (e) too much government, (f) low profit margins and competition from large, name brand FBO's, (g) poor management, (h) poor marketing, (i) fewer FBO's due to the range capability of the corporate fleet and their ability to "tanker" to get cheap (normally home-based) fuel, (j) industry consolidation, and (k) smaller airports cannot support a business operation without subsidies.
Nineteen percent of the survey participants reported that the number of airport service businesses remained the same over the past five years. Respondents cited that general economic stability, and the number of FBOs leaving the market are equal to those entering it, as primary influences for a lack of growth or decline in the number of airport service businesses.

\section{FBO's Over the Next 5 Years}

Participants were asked the following question: "In your opinion, will the number of airport service businesses increase, decrease, or remain the same over the next five years?" Participants were asked to provide responses to this question in three categories: local, statewide and nationwide levels. They were given three status responses to reflect their opinions: increase, decrease, or remain the same (see Table 7). Participants were also asked to provide rationale for their opinion.

Local.

Twenty-one percent of participants forecast an increase in the number of airport service businesses over the next five years. Rationale provided by respondents for an increase in the number of airport service businesses over the next five years were: (a) strong economy, (b) our city is growing, (c) must expand to meet higher rent and insurance costs, (d) offer more services by independent operators to enhance the value of the airport to the community, (e) people seem to have more money to spend on aviation, and (f) new entrants are considerably younger and more aggressive in business.

Twenty-five percent of participants forecast a decrease in the number of airport service businesses over the next five years. Rationale provided by respondents for an decrease in the number of airport service businesses over the next five years was: (a) less general aviation activity at small airports, (b) corporate aviation strong and growing, (c) competition, (d) product liability and frivolous lawsuits, (e) a need for a major draw i.e., service center, (f) Environmental Protection Agency underground storage tank regulations and insurance costs place a heavy burden on small businesses, (g) a lack of business, (h) tighter regulations, (i) increased cost of operations, (j) shrinking manpower pool, and (k) increase in aircraft rental/charter costs and a decrease in corporate travel budgets. 
Table 5

Opinions of Respondents - Numbers of FBO's: Past Five Years

\begin{tabular}{lcll} 
& & FBO Status & \\
\multicolumn{1}{c}{ Category } & Increase & Decrease & Remain the Same \\
\hline & & & \\
Local & 11 & 11 & 28 \\
Statewide & 8 & 24 & 11 \\
National & 7 & 26 & 9 \\
\hline
\end{tabular}

Note. $\underline{n}=49$. All respondents did not respond to all categories.

Table 6

Opinions of Respondents - Numbers of FBO's Statewide: Past Five Years

\begin{tabular}{|c|c|c|c|}
\hline Category & Increase & $\frac{\text { FBO Status }}{\text { Decrease }}$ & Remain the Same \\
\hline North & 4 & 13 & 2 \\
\hline Central & 2 & 7 & 2 \\
\hline South & 2 & 4 & 7 \\
\hline
\end{tabular}

Note. $\underline{n}=48$. All respondents did not respond to all categories. Also, this table depicts only the statewide portion of the data shown in Table 5. 
Table 7

Opinions of Respondents - Numbers of FBO's: Next Five Years

\begin{tabular}{lccc}
\hline \multirow{2}{*}{ Category } & Increase & $\frac{\text { FBO Status }}{\text { Decrease }}$ & Remain the Same \\
& & & 28 \\
Local & 10 & 12 & 17 \\
Statewide & 9 & 20 & 16 \\
National & 8 & 22 & \\
\hline
\end{tabular}

$\underline{\text { Note. }} \underline{\underline{n}}=50$. All respondents did not respond to all categories.

Over fifty-eight percent of participants forecast that locally airport service businesses would remain the same over the next five years. Rationale for this stability was: (a) there is an increased cost associated with operating an FBO, (b) no increase in business due to higher prices resulting from product liability suits, (c) economic stability, (d) insufficient business for more than one FBO, (e) growth has peaked, (f) smaller airports cannot support business operations without subsidies, $(\mathrm{g})$ cost to enter the business is very high and profit margins slim, (h) changes in the aircraft fleet, static in number, but growing in numbers of jets, and (i) the airport authority promotes competition as long as the businesses remain viable.

\section{Statewide.}

Nineteen percent of participants forecast an increase in the number of airport service businesses over the next five years. Rationale provided by respondents for this increase was: (a) strong economy, (b) airports improve their facilities and available services, (c) interstate highways crowded and dangerous, (d) shortage of pilots and mechanics, (e) people seem to have more money to spend on aviation, and $(f)$ increased interest in aviation.

Forty-two percent of participants forecast a decrease in the number of airport service businesses over the next five years. Rationale provided by respondents for the decline was: (a) less general aviation activity at small airports with corporate aviation growing strong at larger airports; (b) competition; (c) product liability and frivolous lawsuits; (d) a need for a major draw i.e., service center; (e) Environmental Protection Agency underground storage tank regulations and insurance costs place a heavy burden on small businesses; (f) a lack of business; (g) tighter regulations, increased cost of operations, and a shrinking manpower pool; (g) over-priced, over-regulated operating environments, consolidation of operations/operators; (h) rising costs and low profit margins; (i) operators can't match government money; and (j) ineffective marketing.

Thirty-five percent of participants forecast that the number of airport service businesses over the next five years would remain the same. Rationale provided by respondents in this category was: (a) an increased cost associated with operating an FBO, (b) no increase in business due to higher prices resulting from product liability suits, (c) strong economy, (d) interstate highways crowded and dangerous, (e) new aircraft available, (f) airlines expanding, $(\mathrm{g})$ shortage of pilots and mechanics, (h) increased interest in aviation, and (i) people seem to have more money to spend on aviation.

A graphic depiction (see Appendix F) of the "statewide" level responses indicates that respondents located north of Kankakee (including the Chicago area) were pessimistic about the numbers of FBO's or general aviation service businesses over the next five years. A majority of these respondents $(52.3 \%)$ forecast a decrease in FBO numbers, while $41.2 \%$ believe that FBO numbers will remain the same. Only $37.5 \%$ of these respondents forecast an increase in the number of FBO's. Respondents from the middle part of the state (Galesburg south to Taylorville and Mattoon) were almost equally pessimistic with $45.4 \%$ forecasting a decrease in $\mathrm{FBO}$, and $12.5 \%$ of these respondents forecasting an increase in FBO numbers. The rest indicated no change over the next five years. However, southern Illinois respondents were considerably more positive in their responses. Twenty-three point eight percent forecast 
a decrease in number the number of FBOs. An equal amount, $23.8 \%$, forecast that FBO's numbers will remain the same over the next five years. Fifty percent of these respondents believe that there will be an increase in the number of FBOs. This is the largest number of "increase" responses in any of the state's three regions. See Table 8. Nationally.

As reflected in Table 7, 17\% of the respondents forecast an increase in the number of airport service businesses over the next five years. Rationale provided by respondents for this increase was: (a) new aircraft sold to the super rich, (b) strong economy, (c) interstate highways crowded and dangerous, (d) new aircraft available, (e) airlines expanding, and (f) shortage of pilots and mechanics.

Forty-six percent of participants forecast a decrease in the number of airport service businesses over the next five years. Rationale for the decline was: (a) smaller airports cannot support business operations without subsidies; (b) increased costs associated with the FAA; (c) over-priced, over-regulated operating environments, and consolidation of operations/operators; (d) operators can't match government money; (e) rising costs, low profit margins, and competition from large brand name FBO's; (f) increased competition will result in consolidation; (g) lack of marketing; (h) increased cost and decreased profits; (i) corporate aviation is strong and growing; (j) small airports difficult to survive without major draw i.e. service center; (k) Environmental Protection Agency underground storage tank regulations and insurance costs place a heavy burden on small businesses, and (l) tighter regulations, increased cost of operations, and a shrinking manpower pool.

Thirty-three percent of participants forecast that the number of airport service businesses in next five years would remain the same. Rationale for this stability was: (a) an increased cost associated with operating an FBO, (b) no increase in business due to higher prices resulting from product liability suits, (c) economic stability, (d) changes in the aircraft fleet, static in number, but growing in numbers of jets, and (e) very high initial investment with marginal returns on investment.

Table 8

Opinions of Respondents - Numbers of FBO's Statewide: Next Five Years

\begin{tabular}{|c|c|c|c|}
\hline Category & Increase & $\frac{\text { FBO Status }}{\text { Decrease }}$ & Remain the Same \\
\hline North & 3 & 11 & 7 \\
\hline Central & 1 & 5 & 5 \\
\hline South & 4 & 5 & 5 \\
\hline
\end{tabular}




\section{Likely Structural Changes in the FBO Industry}

Survey participants were asked to rank FBO structural changes that they felt would take place in the next five years. A total of 47 respondents provided input to this question. The survey revealed that the most likely (ranked \#1) structural changes, in descending order, were: (a) increased FBO specialization, (b) single FBO's joining chains, and (c) an equal ranking for more focus on corporate jet customers and less focus on general aviation customers. Conversely, the least likely (ranked \#6) structural changes, in descending order, were: (a) an equal ranking for single FBO's joining chains and other, (b) increased specialization, and (c) consolidation among FBO chains. Table 9 provides an illustration of these rankings. An interesting comparison was revealed when the most likely rankings, \#1, \#2, and \#3, were added together. The result was a somewhat different forecast of the "Most Likely" structural changes for the next five years. For example, "more focus on corporate jet customers" ranks first (rather than tied for third). The same result was found to be true when the least likely rankings, \#4, \#5, and \#6, were added together. For example, "consolidation among chains" received the most \#4, \#5, and \#6 responses, versus being third "Least Likely." Table 10 provides a comparison of the most likely ranking (\#1) to the aggregate most likely rankings (\#1, \#2,\#3). Included in Table 10 is a comparison of the least likely ranking (\#6) to the aggregate least likely rankings (\#4, \#5, \#6).

Table 9

\section{Likely Structural Changes}

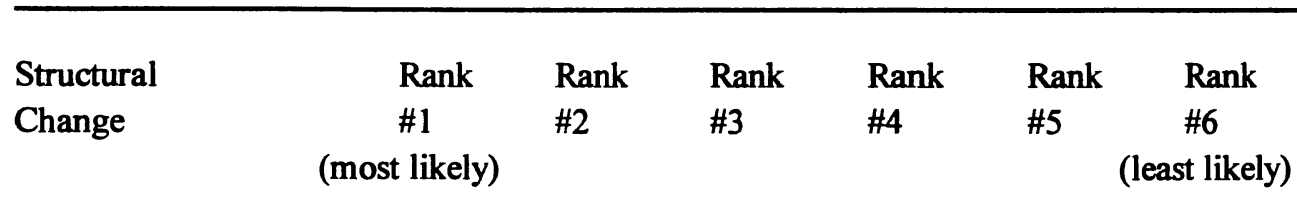

\section{Increased FBO}

specialization

Single FBO's

joining chains

Consolidation

among FBO chains

24

12

11

8

4

More focus on

corporate jet

customers

$11 \quad 12$

11

8

1

1

Less focus on general aviation customers

115

Other $^{\mathrm{a}}$

$1 \quad 2$

2

0

6

Note. $\underline{n}=47$. Respondents ranking structural changes were inconsistent in that some ranked a structural change (1-6) more than once while some respondents did not rank a structural change at all. ${ }^{a}$ Other represents responses not fitting the previous categories. 
Table 10

Comparison of Structural Changes

$\begin{array}{lrccc} & & \text { Aggregate } & \text { Aggregate } & \\ & \text { Most Likely } & \text { Most Likely } & \text { Least Likely } & \text { Least Likely } \\ \text { Structural } & \text { Rank } & \text { Ranked as } & \text { Ranked as } & \text { Rank } \\ \text { Change } & \# 1 & \# 1, \# 2, \text { or \#3 } & \# 4, \# 5 \text {, or \#6 } & \# 6\end{array}$

Increased FBO

specialization

$16(1) \quad 33(2) \quad 14(3) \quad 5(2)$

Single FBO's

joining chains

$13(2)$

$31(3)$

$14(3)$

$6(1)$

Consolidation among FBO chains

$18(5)$

$23(1)$

$4(3)$

More focus on corporate jet customers

$11(3) \quad 34(1) \quad 10(4) \quad 1(5)$

Less focus on general aviation customers $25(4)$ $20(2)$ $4(3)$

Other $^{\mathrm{a}}$ $1(5)$ $5(6)$ $6(5)$ 6(1)

Note. $\underline{\underline{n}}=47$. Respondents ranking structural changes were inconsistent in that some ranked a structural change more than once while some respondents did not rank a structural change at all. Numbers in parenthesis indicate descending order ranked. ${ }^{a}$ Other represents responses not fitting the previous categories. 


\section{FBO's Reported As Closing}

Nine respondents indicated that their FBO would close in the next five years. Additionally, as indicated by the survey, some operators identified multiple reasons for closure. In descending order operators provided the following rationale for closure: (a) five indicated that environmental issues, concerns, or regulation; (b) three cited safety regulatory issues and off-site competition; and (c) two indicated increased fuel cost and on-airport regulations and competition. Eight respondents cited additional, unique reasons for closure that included: (a) privately owned land could be sold, (b) higher rent and insurance premiums, (c) lack of airport development due to poor management, (d) liability, perception/cost of insurance unrelated to reward, (e) self fueling, tailgate mechanics, and free-lance flight instructors, (f) owner wants to retire, (g) customer base is declining, and (h) Federal government, small business regulations, record keeping, rules, etc.

\section{CONCLUSION}

The results of this study indicate that there were at least 118 Fixed Base Operators at 128 public use airports in Illinois in 1998. Because 54 airports do not have a listed FBO, the 118 existing FBO's serve 74 airports with 16 airports having multiple FBO's. This survey of Illinois FBO's indicated that the average respondent FBO: (a) provides nine separate aviation services, (b) owns 6.4 aircraft, (c) employs 19.8 people, (d) has a payroll under $\$ 250,000$, (e) has $\$ 500,000$ or more in annual revenue, (f) has been in business an average of 21 years, and $(\mathrm{g})$ has 1.1 competing FBO's on the same airport.

When asked about the number of FBO's over the past five years at local, statewide, and national levels, respondents indicated the following opinions: (a) local FBO numbers have remained the same $(58.3 \%)$, (b) statewide FBO numbers have decreased $(50.0 \%)$, and (c) national FBO numbers have decreased (54.0\%).

When asked about FBO's over the next five years, respondents indicated the following opinions: (a) local FBO numbers will remain the same (58.3\%), (b) statewide FBO numbers will decrease (42.0\%), and (c) national FBO numbers will decrease (46.0\%).

However, respondents did indicate a somewhat more optimistic view of the future of statewide and national FBO numbers. For example, the number of respondents indicating increases over the next five years is slightly larger than the number of respondents indicating an increase for the past five years. And, their view of local FBO numbers is virtually static when comparing future five-year numbers to the past five year numbers. Therefore, it can be seen that respondents do not have an overwhelming sense of FBO growth in the future. On the other hand, there seems to be a cautious optimism about future business prospects, particularly at the statewide and national levels.

When asked about likely structural changes in the FBO industry, respondents indicated that increased FBO specialization, more focus on corporate jet customers, and single FBO's joining chains as the three most likely changes when considering aggregate responses. Consolidation among FBO chains and less focus on general aviation customers were considered the least likely changes among aggregated survey responses. Finally, a total of nine respondents indicated that their FBO would close in the next five years. A key reason given included environmental issues, concerns, and/or regulations.

This article was an attempt at conducting a "pilot study" to gauge attitudes and perceptions of Illinois FBOs owners/operators as they relate to the status of the FBO industry. This study has served to indicate the need for additional study, particularly at the national level. $\square$ 
D. Scott Worrells earned a Master of Science in Aviation Management, a Bachelor of Science in Aviation TechnologyAvionics, and a Associate of Science in Aviation Maintenance Management from Embry-Riddle Aeronautical University. He is an Assistant Professor, Department of Aviation Management and Flight at Southern Illinois University Carbondale.

Jose R. Ruiz earned a Master of Aeronautical Science from Embry-Riddle Aeronautical University; a Bachelor of Science in Human Resource Management from Park College. He is an Assistant Professor, Department of Aviation Management and Flight at Southern Illinois University Carbondale.

David A. NewMyer earned a Master of Arts in Metropolitan Studies from Drew University, a Master of Science in Transportation from Northwestern University, and a Ph.D. in Education Administration and Higher Education from Southern Illinois University Carbondale. He is an Associate Professor and Chairperson, Department of Aviation Management and Flight at Southern Illinois University Carbondale. 


\section{REFERENCES}

Airport directory. (1996). Frederick, Maryland: Aircraft Owners and Pilots Association.

The Aviation \& Aerospace Almanac 1999 Edition. (1999). NY: McGraw-Hill Companies, Inc.

Department of Transportation: Federal Aviation Administration. (1999). FAA aerospace forecasts: Fiscal years 1999-2010. (FAA-APO-99-1). Washington, DC: Author.

Aeronautics.

Illinois airport directory. (1997/1998). Springfield, Illinois: Illinois Department of Transportation, Division of

Infanger, J.F. (1999, September). Strategic evaluations. Airport Business, 13, 17-21.

Lowe, P. (2000, April). FAA sees growth in all aviation, but fuel costs could present a hurdle. Aviation International News, 32, 28.

Membership directory. (1994/1995). Urbana, Illinois: Illinois Aviation Trades Association.

Phelps, M. (2000, May). The other side of the windshield. Aviation International News, 32, 34-36.

World aviation directory. (1998). Washington, DC: McGraw-Hill. 


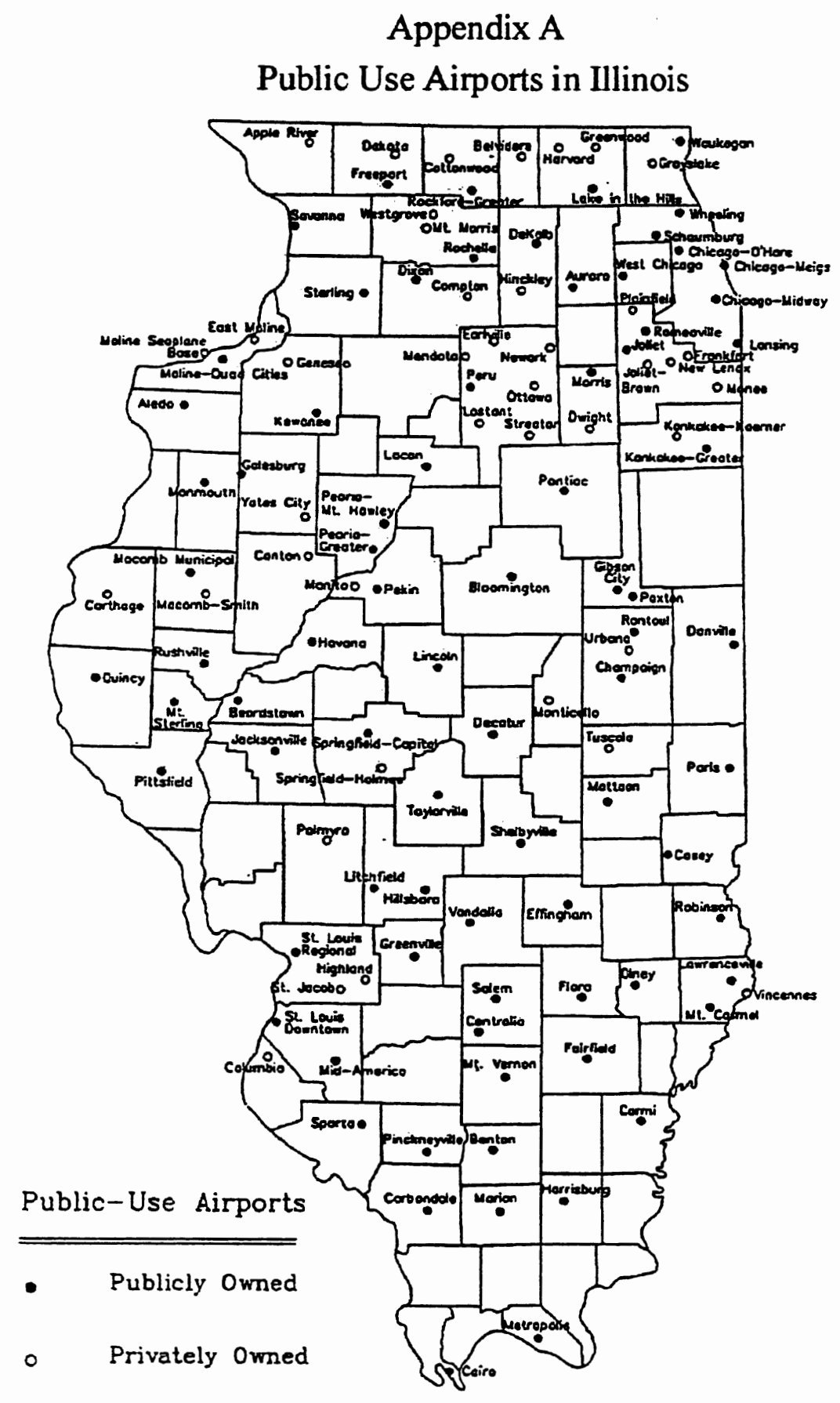




\section{Appendix B}

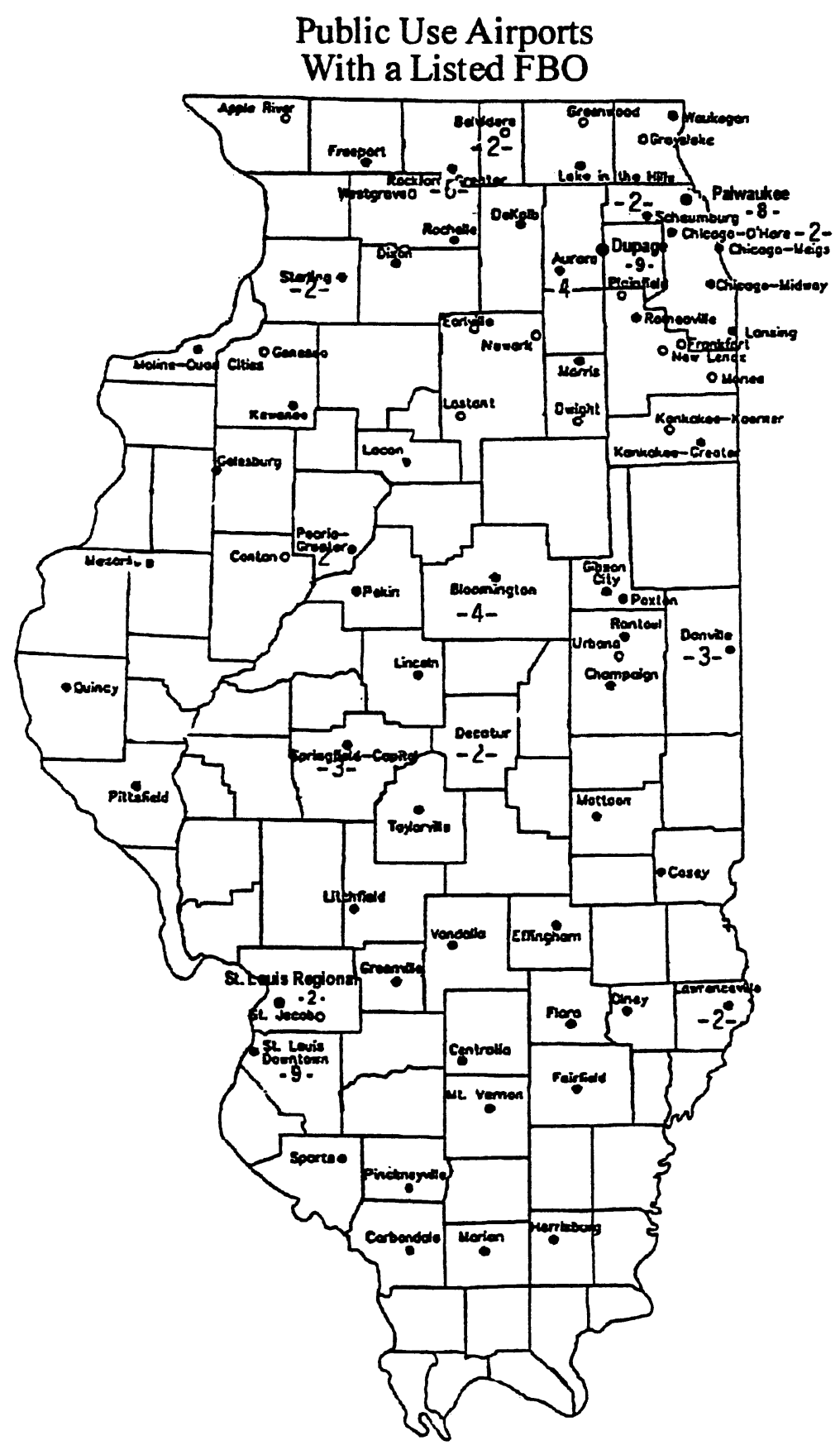




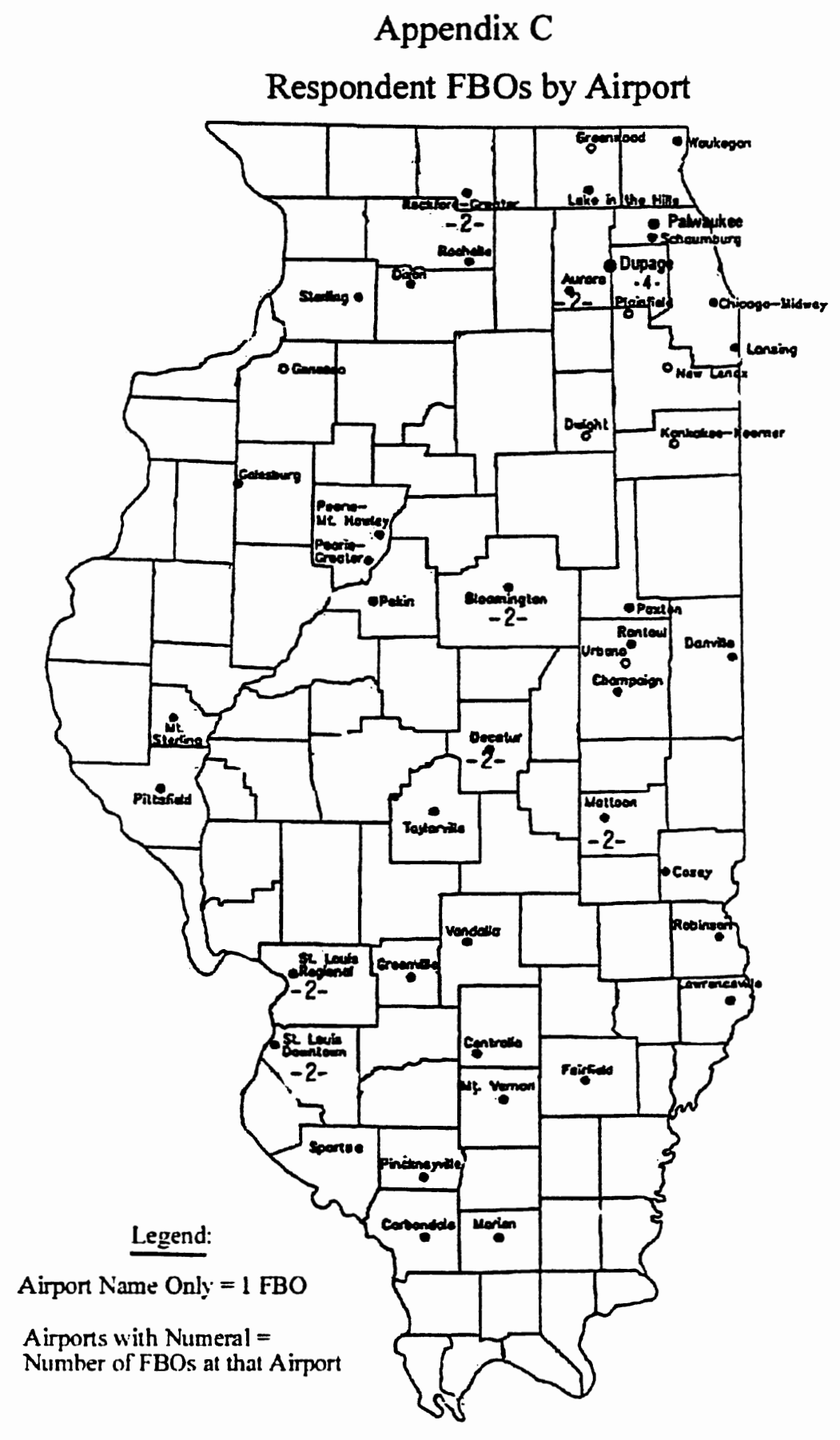




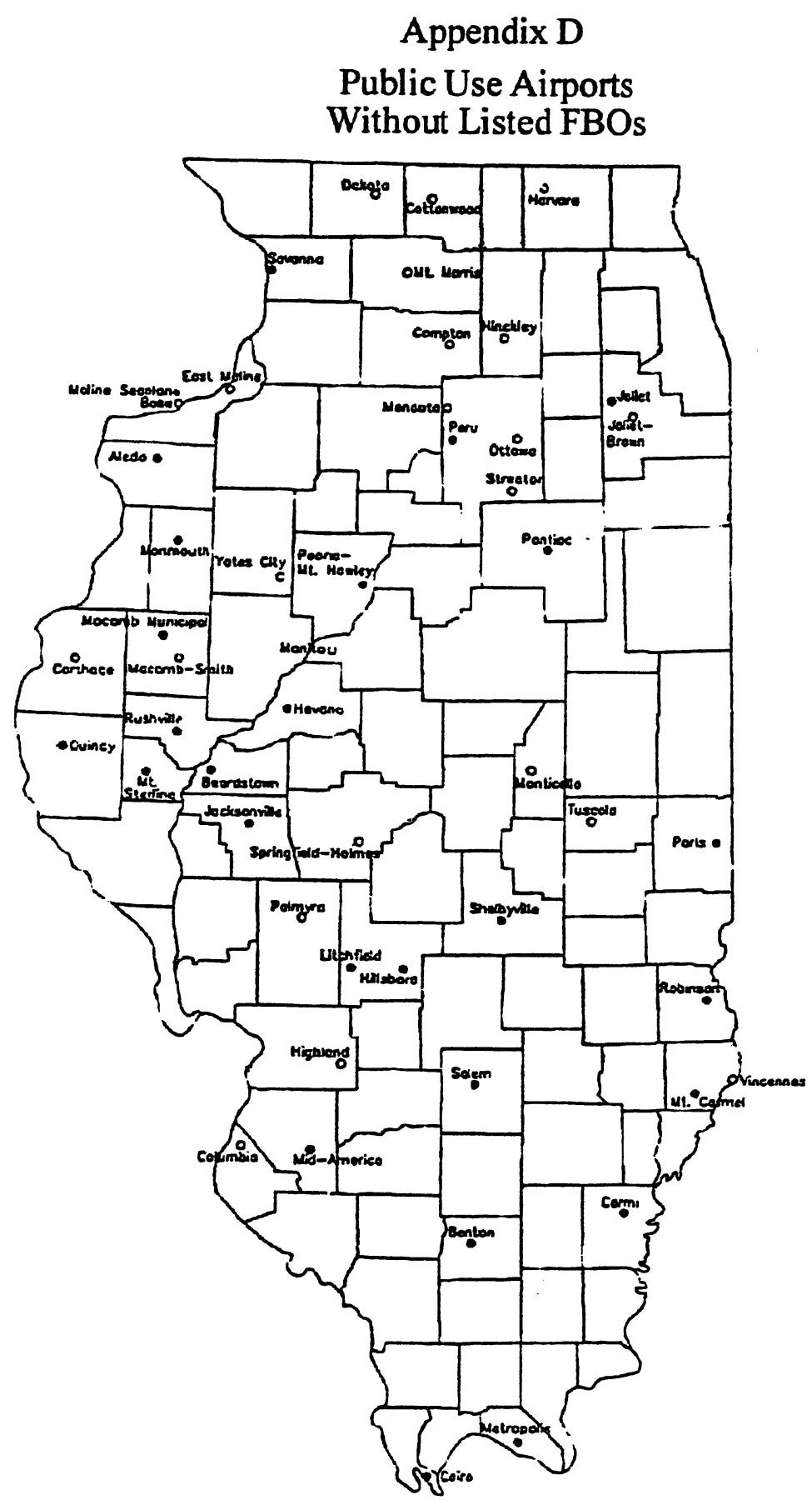




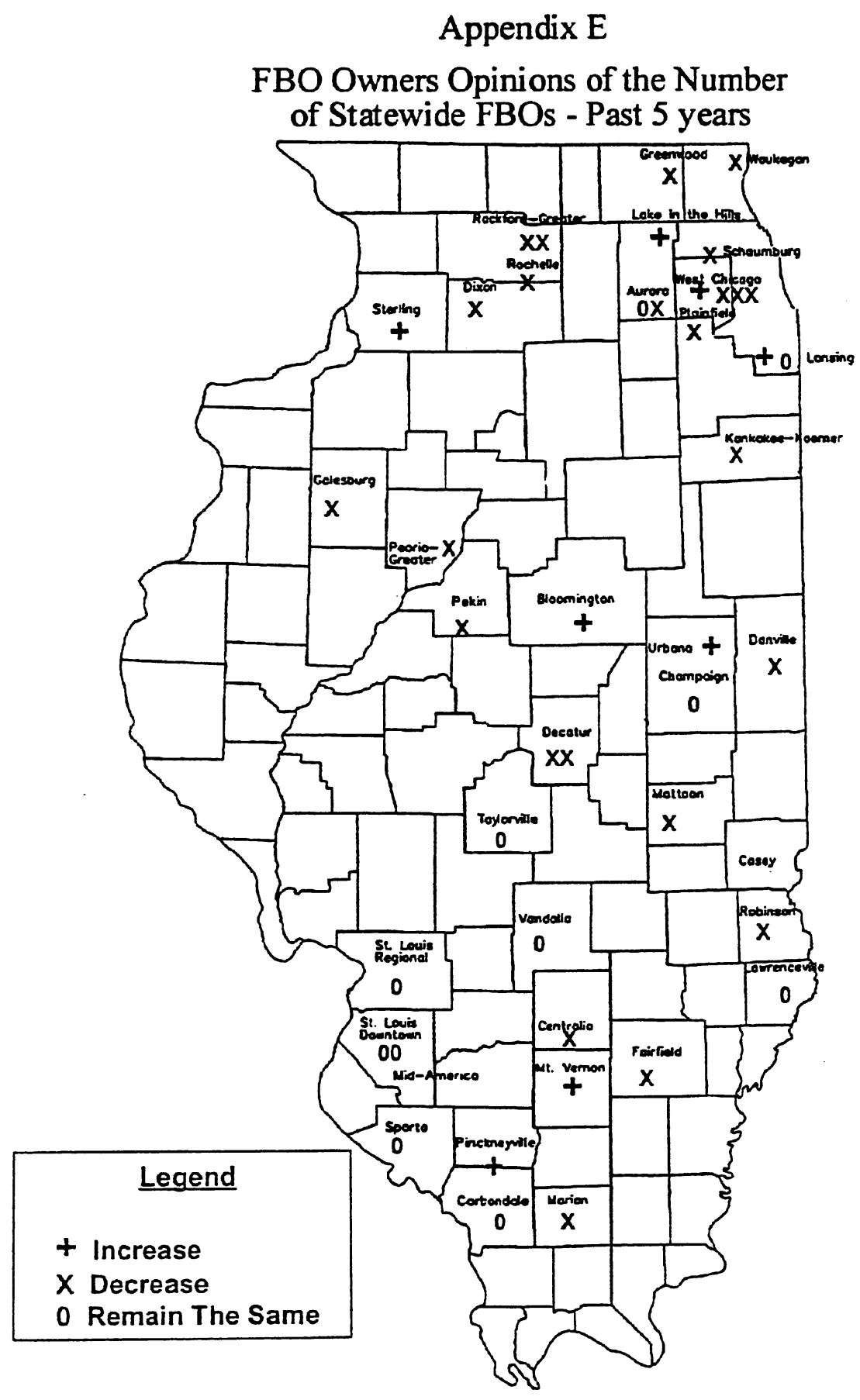




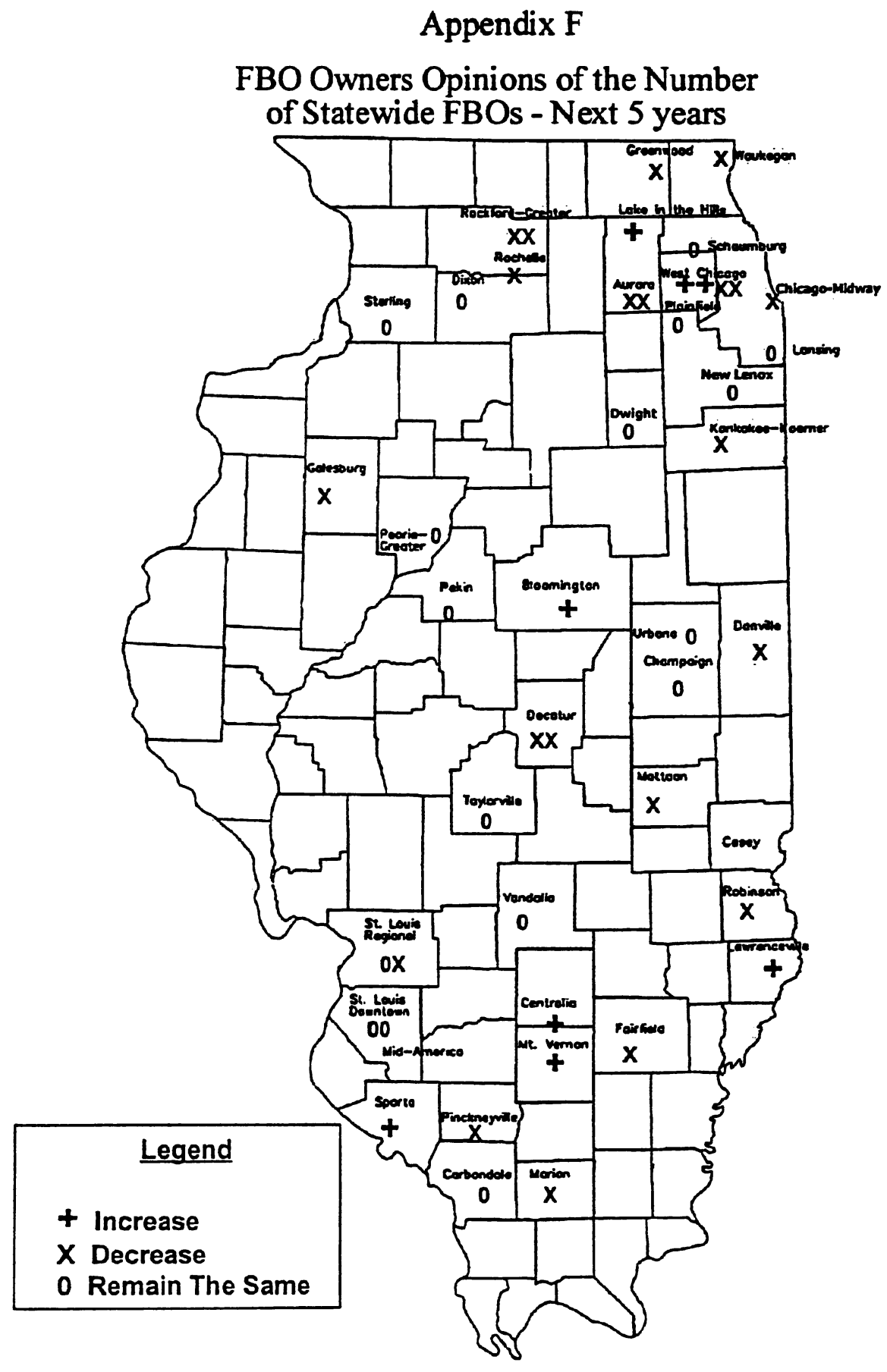


